\title{
Objectives over Time: A Look at Four Decades of Objectives in the Educational Research Literature
}

\author{
James Marken \\ Virginia Beach Public Schools, United States \\ Gary Morrison \\ Old Dominion University, United States
}

\begin{abstract}
While the concept of objectives is widely used in many applied fields of instruction, the systematic derivation and application of objectives for learning and instruction is a key feature of systematic instructional design. However, the treatment of objectives and the terminology surrounding them is sometimes nebulously employed. This article takes a historical look at the terminology around objectives used in the research literature to track changes over time. Data base searchers were conducted using Academic Search Complete, Education Research Complete, and ERIC to identify various terms using nine different objective related terms. Searches were limited to peer-reviewed sources, and restricted by date to include only the 1970s, 1980s, 1990s, and 2000s respectively. Results show that terms with more concrete definitions, such as behavioral objectives, have fallen off markedly, while terms with more operational definitions, such as educational objectives or learning objectives, have gained in currency. Implications for the field of instructional design are discussed.
\end{abstract}

Keywords: Objectives; Instructional design; Behavioral objective; Cognitive objective;

Performance objective

\section{Introduction}

Perhaps the greatest contribution the field of instructional design has made is the systematization of the instructional process. One of the most important parts of that systematization has been the use of objectives to drive the instructional design process (Morrison, Ross, Kalman, \& Kemp, 2013; Dick, Carey, \& Carey, 2008; Gagné, Briggs, \& Wager, 1992). While these authors (and others) all suggest that objectives are an important part of the instructional design process, they use different terminology. This variance in terminology will be explored in this paper; what unites the various flavors of objective is that they define a desired outcome to the instruction in question.

Although there has been disagreement about whether objectives should be given to students (Duchastel \& Merrill, 1973), be developed in conjunction with students (Denton, 1974; Wight, 
1972), or are primarily for use by instructors as a way of focusing their design (Bailey, 1977; Drumheller, 1974), few instructional designers would argue that objectives should not be included in the design process. To the contrary, researchers and practitioners have spent a great deal of time and energy exploring different types of objectives and the circumstances under which they are applicable.

\section{Terminology of Objectives}

Some of the primary terms used in the instructional design literature to refer to objectives include behavioral objectives, cognitive objectives, learning objectives, educational objectives, and instructional objectives. In some cases, the terms are functionally synonymous. In others, there are differences in both function and structure. The terms learning objective, educational objective, and instructional objective are especially common as catch-all terms and used in generic ways. For example, some authors use learning objective to refer to more general objectives (Schamber \& Mahoney, 2006; Mulholland, Wolff, Zdrahal, \& Collins, 2008); Novakowski (2009) use the term educational objective in a similarly broad manner. d'Ham, de Vries, Girault, and Marzin (2004) provide examples of how they define learning objectives, "Identify objects and phenomena and become familiar with them, Learn a fact or facts, Learn how to carry out a standard procedure" ( $p$. 427), which suggest a structure similar to a Tyler-type objective (Tyler, 1971).

The IMS Reusable Definition of Competency or Educational Objective - Information Model (IMS Global Learning Consortium, 2002) offers a definition of educational objectives for the purpose of "describing, referencing, and exchanging definitions of competencies" (para 1). Similar to a behavioral objective, they state that the educational objective or competency should including the behavioral verb, conditions, and criteria. These articles and the definition suggest that the terms educational objective and learning objective differ from the generally accepted definition of a behavioral objective.

In this article, we will explore the usage of the different terminologies, summarize the various forms of objectives presented in the literature, and provide a historical perspective on the use of objectives in the field of instructional design. The question guiding this article is: What changes have occurred over the past four decades in the use of objectives in instructional design? To answer this question, literature searches on various types of objectives were completed for 1970 through 2009 by decade. The databases used were Academic Search Complete, Education Research Complete, and ERIC. The trends over these four decades were then analyzed, and the results synthesized into an overall view of objectives and what they mean for the field of instructional design.

\section{Types of Objectives}

In the following sections, we will explore the concepts of Tyler-style, behavioral, and cognitive objectives that form the foundation for this analysis. Constructivists generally do not focus on specific objectives, especially pre-defined instructor-driven objectives as traditionally stated by 
instructional designers and teachers. Rather, as the following quote by Bednar and her coauthors demonstrates, their focus is on outcomes as negotiated between the learner, the instructor, and the environment. "...constructivists do not have learning and performance objectives that are internal to the content domain (e.g., apply the principle), but rather we search for authentic tasks and let the more specific objectives emerge and be realized as they are appropriate to the individual learner in solving the real-world task" (Bednar, Cunningham, Duffy, \& Perry, 1992, p. 25). This approach is in contrast to the traditional instructional design approach that defines objectives early in the design process and then uses the objectives to develop instructional prescriptions (Morrison et al., 2013; Dick et al., 2008; Gagné et al., 1992).

\section{Tyler-style Objectives}

Tyler holds an important place in the history of educational technology (Saettler, 1990). His system of specifying objectives was in many ways the forerunner to the modern behavioral objective (Tumposky, 1984), and even shares similarity with Gronlund's (2004) cognitive objectives. Tyler (1931) focused specifically on behavior, and was a strong critic of nebulous objectives that failed to provide sufficient substance to make solid judgments about whether or not the objective in question had been achieved. Much of Tyler's focus was on crafting objectives in such a way that those solid judgments could be reached. Like Gronlund, Tyler also included ostensibly nebulous terms like "appreciate" as the action part of the objective. Tyler's unique approach was to split the objective into two aspects: the behavioral aspect and the content aspect. As Tyler states, "...the objective, 'To write clear and well-organized reports of social studies projects,' includes both an indication of the kind of behavior-namely, writing clear and well-organized reports-and also indicates the areas of life with which the reports are to deal" (Tyler, 1971, p. 47). The content aspect (the "areas of life") is reminiscent of Mager's conditions, but it is not equivalent as Mager's conditions are more specific. Tyler lacks an analogy to Mager's criteria, except to the extent that the objective writer specifically includes it. Tyler's content aspect provides the context for the behavioral portion of the objective. As a result of his focus on curriculum development, Tyler further advocated grouping related objectives into larger units. This grouping allowed the objective writer to then map the two aspects (i.e., verb and content) against each other in a grid for a series of objectives and a corresponding list of content areas. For example, a biology course might require the student to interpret data or apply principles (behaviors) for human nutrition or the respiratory system (content) (Tyler, 1971, p. 50). Specific lessons (with more detail on the behavior the students must demonstrate-perhaps even including what Mager would call "criteria") could then be built around each relevant cell in the grid. (Not all cells would necessarily be part of the overall curriculum.)

\section{Behavioral Objectives}

The terms behavioral objectives and Mager-style objectives are generally synonymous. These objectives generally start with a condition such as "Given the necessary tools." Next is a behavioral verb, that is, one that is either directly observed such as removing a spark plug or indirectly observed through the results as in solving a math story problem. The last component is the criteria 
that define the accuracy level such as "within $1 / 8$ of an inch" or " 9 out of 10 correct." While Mager (1962) did not explicitly state that an objective should include a mention of the content, his examples do include the content that is the focus of the behavioral verb. The verb is generally explained by pairing it with specific content such as solving 10 basic addition problems.

Claimed advantages of behavioral objectives include guiding the teacher's planning (Drumheller, 1974; Reti, 1975; Woodruff \& Kapfer, 1972), guiding the design of the instruction (Morrison et al. 2013; Dick, et al. 2008), increasing student engagement (Denton, 1974), an aid to testing (Reti, 1975; Woodruff \& Kapfer, 1972), and increasing student achievement (Anderson \& Fowler, 1978; Martin \& Bell, 1977; Snider, 1975). Researchers who found increased achievement also offered caveats, such as the gain in achievement depends on the learner's ability level (Johnson \& Sherman, 1975) or on the teaching strategies, task characteristics, and learner characteristics (Hartley \& Davies, 1976). Other critics maintain that behavioral objectives are prone to triviality (Wight, 1972) and thus do not measure what is important (MacDonald-Ross, 1973; Posner \& Strike, 1975), disempower the student at the expense of the teacher (Wight, 1972), and are boring (Thiagarajan, 1973). Melton (1978) concluded that the research on whether objectives influence achievement was inconclusive and required consideration of a number of factors. However, instructional objectives are one of the most used design steps by instructional designers. Tessmer \& Wedman (1990) suggested the specification of objectives is determined by the need for preciseness whereas goals may be more appropriate when the designer cannot specify the detailed objectives within an appropriate timeframe. However, studies of practicing designers found that the use of objectives was one of the most frequently completed tasks (Christensen \& Osguthorpe, 2004; Wedman \& Tessmer, 1993) performed by instructional designers. In an analysis of multiple studies of the practice of instructional design, Leigh and Tracey (2010) found specifying of objectives was one of the most frequently cited tasks.

\section{Cognitive Objectives}

At the 1978 annual convention of the American Education Research Association, the era of Behaviorism in education was "officially" declared to have ended, replaced by cognitive paradigms of learning (Low, 1980). Despite this declaration, cognitivism has not spawned a widely used unique type of objective, which has a widely agreed upon and recognizable form comparable to the behavioral objective. There are three distinct types of cognitive objectives that vary primarily in form rather than function. These three forms are described in the following paragraphs.

\section{Behavioral Objectives as Cognitive Objectives}

Often, when authors describe cognitive objectives, they are referring to traditional behavioral objectives written in the cognitive domain of Bloom's (1956) taxonomy (Gansneder, Caldwell, Morris, Napier, \& Bowen, 1977; Peček, Zuljan, Čuk, \& Lesar, 2008; Sandler \& Kamins, 1987; Teague $\&$ Michael, 1994). These objectives include the verb (plus content), condition, and criteria of a traditional Mager-style behavioral objective; however, their focus is generally on behaviors 
specified in the higher levels (e.g., application and above) of Bloom's (Bloom et al., 1956) taxonomy.

\section{Greeno's Cognitive Objective}

An obscure but distinct form of cognitive objective is described by Greeno (1976). Greeno's cognitive objectives attempt to create an explicit mental map or schema around a particular concept or procedure that often resemble flowcharts. The objectives are intended to represent the knowledge structures a learner needs to apply the learned material. Thus, they could be thought of as a model. Greeno's cognitive objectives do not replace behavioral objectives; rather they provide the instructor a different way to approach the question of the strategies they will employ in the instruction. Rather than focusing on what the student has to do (behaviorally) to demonstrate that they've learned the material, cognitive objectives focus on what the student has to know. According to Greeno, if they know it, they can presumably do it-even with cognitive objectives, assessment should be based on observable behavior. Although cognitive objectives are intended to represent the learners' mental models or schema, it is not a claim of cognitive objectives that there is only one "right" mental model or schema in question. As long as the model is reasonable, it is considered to be a cognitive objective by Greeno's definition.

\section{Gronlund's Cognitive Objectives}

Gronlund $(1985,2004)$ has long advocated a distinct approach to objectives that combines the specific and behavioral with an over-arching general framework. It is important to acknowledge that Gronlund (2004) does not describe his objectives in this way, but calling them behavioral objectives in a cognitive wrapping is not unreasonable. With Gronlund-style objectives, the designer first determines the wider aim or goal of the instruction (e.g., the student will interpret a graph). Then, the designer determines a set of specific examples of performance (e.g., student states relationship between variables) that a student could demonstrate to provide evidence the objective was mastered. Verbs like "understand" are appropriate for the more general aims and goals, but not for the performance portion of the objectives. Gronlund-style cognitive objectives differ from a conventional behavioral approach in that the focus remains on the wider aim or goal level, rather than on a single, specific, observable behavior. Conventionally employed behavioral objectives tend to lose that wider focus, with the specific behavioral objectives themselves becoming paramount. Gronlund-style objectives are to some extent an antidote to that way of thinking. Gronlund-style objectives are particularly suited for describing more complex cognitive behaviors (e.g., those at the higher levels of Bloom's taxonomy) that are not easily specified using a Mager-style objective.

To some extent, cognitive objectives reflect an education/training distinction between cognitive and behavioral objectives. Without denying the importance of behavioral objectives when evaluating learning, cognitive objectives focus more on learning per se, rather than a behavioral change. As a result, cognitive objectives often specify a higher level and more general type of knowledge. Behavioral objectives are well suited for near transfer to specific tasks where the lack 
of specificity of cognitive objectives makes them a viable choice for far transfer tasks. It should be noted that there is nothing mutually exclusive about these behavioral and cognitive objectives, and they are easily used together to define outcomes for the same unit of instruction.

\section{Research Question}

This study examines one question: What changes have occurred over the past 4 decades in the use of objectives terminology in the research literature? Answering this question is important for three reasons. First, the answer serves as a historical grounding for present-day instructional designers. Knowledge preservation is important for any discipline or field of study. Instructional design has been around long enough as a field for early knowledge to start to fade away. Second, it helps instructional designers choose the right type of objectives for the specific situations for which they are designing instruction. This selection of the appropriate objective is consistent with Gropper's (1983) premise that an instructional design theory should differentiate between different types of content. Most designers would agree that well-designed instruction is most powerful when tailored to specific situations. Third, it challenges instructional designers to reflect on their own practice and on their theoretical orientation. While it is not the intent of this paper to claim that a particular type of objective is more effective than another, the place of some sort of objective, however formed, in well-designed instruction is well established. In that sense, the trend away from more rigorous and concrete forms of objectives to more operational forms is worth noting. Again, this is not to say (for example) that instruction that lacks by-the-book Magerstyle objectives automatically lacks rigor; it is to say that moving away from such objectives puts more responsibility on the designer.

\section{Method}

To examine the changes in the use of objectives over the past four decades, literature searches were conducted using key terms in three educational databases limiting the search to articles published in educational journals. The databases searched were Academic Search Complete, Education Research Complete, and ERIC, all accessed through EBSCOHost Web through the authors' university library website in the fall of 2009 that identified 3301 journal articles. The search terms were:

- Objectives

- Behavioral Objectives

- Cognitive Objectives

- Learning Objectives

- Educational Objectives

- Instructional Objectives

- Performance Objectives

- Mager-style Objectives

- Tyler-style Objectives 
Searches were limited to peer-reviewed sources, and restricted by date to include only the 1970 s, 1980 s, 1990s, and 2000s respectively. While the 1960 s might also have been an interesting decade to include, at the time the searches were done, the databases used did not include the early 60s, thus the numbers would not have been comparable. A total of 36 searches were performed (nine search terms for each of four decades). Three of the search terms were dropped for further analysis after the initial searches. The term "objectives" yielded an overwhelming number of articles from a broad array of fields. The term was too general to be useful. The terms "Magerstyle objective" and "Tyler-style objective" returned no hits for any of the decades, nor did the simpler "Mager objectives" and "Tyler objectives." This modification left six terms over the four decades for analysis.

The citations returned by each of the searches were saved as an $x \mathrm{xml}$ file and imported into Microsoft Excel ${ }^{\circ}$. The results were then checked for duplicates. Counts (using Excel's counting formulas) were then made of each of the journals to determine how many times a particular journal had returned a citation with the keyword of interest. These counts were then totaled. This process was repeated for each search term for each decade to create a total picture over time.

\section{Results}

Overall findings indicated that the use of objectives in the research literature has changed over time. All of the terms were present across the years, but the frequency of their usage changes, as do the focus of the journals. The total number of references to objectives also rose measurably over time. Determining all of the factors that account for that increase is beyond the scope of this article. The increase may be due to some combination of better indexing of more recent articles, the proliferation of journals and of journal articles, or of the spread of some of these terms from their genesis in the field(s) of education to other areas (e.g., medicine) for whom education and training are paramount.

Our research question asked what changes have there been over the past 4 decades in the use of objectives in the research literature. The highest frequency result in the 1970s was "behavioral objectives" (35\%), with "educational objectives" (30\%) a close second. The pattern reverses in the 80 s, with "educational objectives" (34\%) most frequently cited and "behavioral objectives" (25\%) second. Compared to the 1970's, the number of citations for behavioral objectives dropped by $58 \%$ and the number of citations for educational objectives dropped by $33 \%$. The pattern changes again in the 90s, where "learning objectives" (40\%) were most frequently cited with "educational objectives" (36\%) second. These two terms also dominate the 2000s, with "educational objectives" coming in with the highest frequency (55\%) and "learning objectives" second (29\%). Behavioral objectives, meanwhile, have been cited less frequently in journal articles with a total of $8 \%$ of the citations for the 4 decades compared to the term educational objectives which account for $51 \%$ of the citations during the same time period.

Another way to examine the data is to calculate the percentage each search term was cited during a decade (see Figure 1). Here, the falloff of behavioral objectives ( $35 \%$ to $6 \%$ ) becomes quite obvious, as does the increase in the use of the term "educational objectives" (30\% to 55\%). It's 
also apparent how the terms "educational objectives" (55\%) and "learning objectives" (29\%) dominated the 2000s. There also appears to be a retreat from the term "learning objective" (29\%) in the current decade, though whether or not that becomes a trend remains to be seen. The terms educational objectives and learning objectives account for $79 \%$ of the articles published over the last four decades. Another interesting trend is the increase in the number of articles referring to at least one type of objective published since 2000. During the 1990's there were 295 articles compared to 2676 articles published between 2000 and 2009.

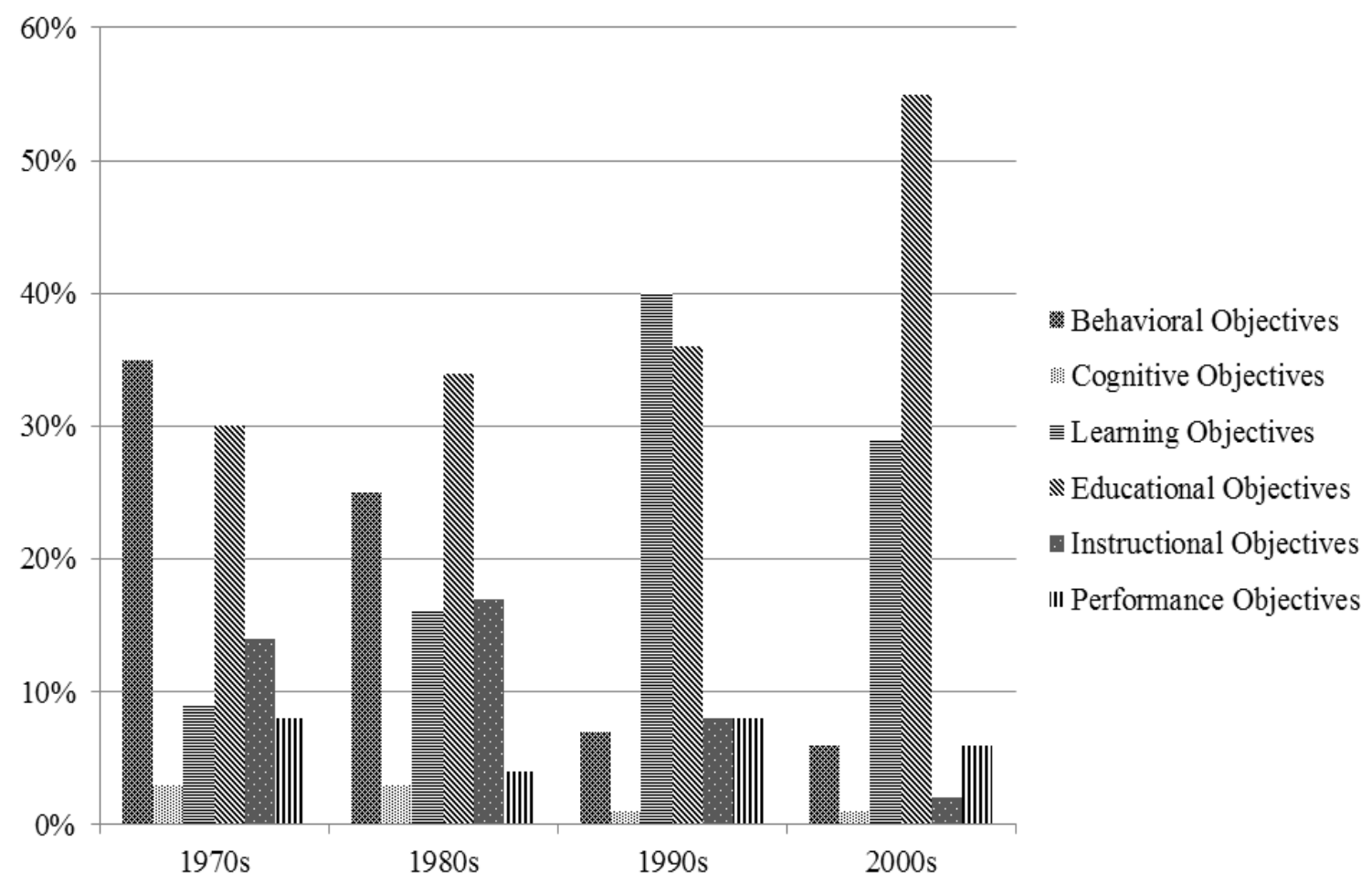

Figure 1. Proportional Occurrence of Each Term by Decade

Another term that appears less frequently in the literature overall and diminishes over time is "instructional objective." Although the term represents a noticeable number of citations during 1970 s and 1980 s ( $14 \%$ and $17 \%$ of the totals, respectively), the term becomes relatively rarer in the 1990 s and 2000 s ( $8 \%$ and $2 \%$ respectively). A final interesting finding revealed in the chart is how the use of the term "performance objective" remains constant. Although the raw numbers fluctuate, in terms of the percentage of the total, the term appears at roughly the same rate across the decades (fluctuating between $4-8 \%$ ). Although many of the journals in which the term is used are engineering or science journals and the researchers may be using the term in a different way than it would be used in instructional design journals, the consistency of the results suggests that there is a consistent focus on performance, however defined. 
There is also a shift in the nature of the journals exploring these topics. During the 1970's, most of the objective citations were in educational journals (e.g., Journal of Teacher Education, Journal of Research in Science Teaching, and Elementary School Journal). In contrast, starting in 2000 to the present, most of the objective citations have an educational focus, but they are from other fields such as medicine and engineering (e.g., European Journal of Engineering Education, Academic Psychiatry, Journal of Structural Engineering). Most noteworthy here is the absence of citations in instructional design journals, or even journals from closely related fields like educational psychology. Citations in these journals are not entirely absent, but they are rarer than one might otherwise expect, especially given that the field of instructional design is in many ways the birthplace of the current concept of an the behavioral objective. The analysis also found that the various terms were found in a broad range of journals. However, the terms educational objective and instructional objective were cited most often in K-12 and teacher education journals, while the terms behavioral objective and learning objective were cited in a broad range of journals.

\section{Discussion}

These findings have several implications for the field of instructional design. For example, the decrease in the frequency of the terms "behavioral objective" and "instructional objective;" given the kinship between behaviorism and instructional design, it is difficult to avoid the suspicion that the two terms may be falling into disuse in tandem. The same forces that have moved the field away from behavioral objectives may also be moving the field away from instructional objectives. If there has been a shift over the last several decades from a focus on training and instruction to a focus on education and learning, then it is perhaps not surprising to see a reduction in the terms instructional and behavioral objectives and a rise in the use of educational and learning objectives. Additionally (or, perhaps, alternatively), it may be that an increased attention to and embrace of constructivist approaches to learning has served to de-emphasize formal objectives, especially ones specifically labeled as being behavioral, which most constructivists would surely reject. To the extent that constructivist approaches would emphasize learning outcomes situated in specific contexts, pre-defined and strictly stated objectives with conditions and criteria become inappropriate. Instead, we have complex, ill-structured systems of which learners must make sense (Winn, 1992). It is interesting that studies of what instructional designers do (Leigh \& Tracey, 2010) all show that the specification of objectives is one of the most frequently performed tasks. Could it be that practitioners are either not writing about behavioral objectives or they are not using the term behavioral or instructional objective?

And yet, despite cognitivism having "officially" replaced behaviorism (Low, 1980) cognitive objectives have neither replaced behavioral objectives nor shown an increase in citations in the research literature. Never popular to start with, their appearance has only lessened with time. Indeed, as a percentage of their respective decades, the most citations that cognitive objectives have been able to achieve (in the 1970s) is still less than the least that behavioral objectives have done (in the 2000s). An alternative explanation is that the uses of objectives, regardless of type, in the instructional design process and for instruction are generally accepted as fact and are no longer of a research interest. 
The increasing use of the terms educational objective and learning objective may be due to the increasing number of citations in education journals that focus primarily on K-12 education. Frequent citations of any of any objective terms in journals focused primarily on instructional design (e.g., Audio-Visual Communications Review, Australian Journal of Educational Technology, British Journal of Educational Technology, Educational Technology Research and Development, Instructional Science, Journal of Instructional Design, and Journal of Interactive Learning Research) or educational psychology (e.g., British Journal of Educational Psychology, Cognition and Instruction, Educational Psychologist, Journal of Educational Psychology) were not evident. The few citations in the mainstream instructional design and educational psychology journals suggest a lack of research and scholarly discussion of objectives in these two fields. This minimal number of articles on objectives, however, should not be interpreted as a lack of interest in objectives as one can find citations in the basic texts of both fields. The finding suggests that researchers are no longer studying the effects of objectives on the design process and on outcomes of student learning.

The results reported here have several implications for the field of instructional design and for the research community in general. One implication has to do with the precision of language. The terms "behavioral objective" and even "cognitive objective" have precise definitions (though the latter, admittedly, has in practice at least three meanings). Terms like "learning objective" or "educational objective" lack a generally accepted definition compared to behavioral objectives and may actually be very general. This lack of definition makes them less precise from an instructional design standpoint. The decline in use of more precise terms like "behavioral objectives" and the rise in more operational terms like "learning objectives" may suggest that the research community is moving away from greater definitional precision to a more operational approach. Similarly, the field of instructional design is no longer investigating the use of objectives in instruction and instructional design, but researchers in other areas-such as K-12-still seem to perceive a need for such studies. Regardless, this change in precision has implications for how researchers in instructional design approach investigations using objectives. Precise definitions of objectives and consistent use of terminology are needed to replicate studies (Combs, Gibson, Hays, Saly, \& Wendt, 2008) and to conduct meta-analyses.

In addition to the question of language, the shift in emphasis on the terms over the years demonstrates how priorities have shifted. Perhaps the lack of current studies is because instructional design researchers are content with the knowledge of behavioral objectives in the instructional process. Research is now focused on learning and instructional strategies as opposed to defining and measuring specific behaviors. Nonetheless, seeing journals from other fields mentioning various flavors of objective in articles serves as important validation of the early research done by educational technologists and instructional designers. These findings may suggest that while objectives are essential to the application of instructional design, researchers are no longer interested in studying objectives and are focusing on newer issues such as problem solving.

Finally, the evolution in the conversation around objectives is further evidence that we as instructional designers would do well to pause and reflect on our use of objectives in practice; and that we as researchers in instructional design would do well to pause and reflect on our own 
theoretical orientations. If concern for or about objectives becomes relegated to textbooks or design manuals rather than the research literature, then to some extent it becomes an exercise most taken seriously by novices, and only given cursory attention by more experienced practitioners or researchers. But if the field of instructional design is in fact moving away from more concrete forms of objectives to more operational ones, then the designer has that much more responsibility for ensuring that the desired learning outcomes are obtained. While various objective terms are used in the instructional design textbooks, the more general field of education has shown a trend to use the terms educational or learning objectives, perhaps due to the influence of the K-12 oriented literature.

\section{References}

Anderson, E. J. \& Fowler, H. S. (1978). The effects of selected entering behaviors and different cognitive levels of behavioral objectives on learning and retention performance in a unit on population genetics. Journal of Research in Science Teaching, 15(5), 373-379.

Bailey, G. D. (1977). Improving classroom instruction with means-referenced objectives. Educational Technology, 17(7), 13-15.

Bednar, A. K., Cunningham, D., Duffy, T. M., \& Perry, J. D. (1992). Theory into practice: How do we link? In T. M. Duffy \& D. H. Jonassen (Eds.), Constructivism and the technology of instruction: A conversation. Hillsdale, NJ: Lawrence Erlbaum Associates.

Bloom, B. S. (1956). Taxonomy of educational objectives: the classification of educational goals. New York: Longmans Green.

Christensen, T. K. \& Osguthorpe, R. T. (2004). How Do Instructional-Design Practitioners Make Instructional-Strategy Decisions? Performance improvement quarterly, 17(3), 45-65.

Combs, K. L., Gibson, S. K., Hays, J. M., Saly, J., \& Wendt, J. T. (2008). Enhancing Curriculum and Delivery: Linking Assessment to Learning Objectives. Assessment \& Evaluation in Higher Education, 33(1), 87-102.

d'Ham, C., de Vries, E., Girault, I., \& Marzin, P. (2004). Exploiting Distance Technology to Foster Experimental Design as a Neglected Learning Objective in Labwork in Chemistry. Journal of Science Education and Technology, 13(4), 425-434.

Denton, J. J. (1974). Student and teacher cooperatively selected behavioral objectives. Audiovisual Instruction, 19(5), 11-12.

Dick, W., Carey, L., \& Carey, J. O. (2008). The systematic design of instruction (7th ed.). Columbus, $\mathrm{OH}$ : Pearson.

Drumheller, S. J. (1974). Behavioral objectives as learning inhibitors: A dilemma and a solution. Educational Technology, 14(10), 17-20.

Duchastel, P. C. \& Merrill, P. F. (1973). The effects of behavioral objectives on learning: A review of empirical studies. Review of Educational Research, 43(1), 53-69. 
Gagné, R. M., Briggs, L. J., \& Wager, W. W. (1992). Principles of instructional design (4th ed.). Fort Worth: Harcourt Brace Jovanovich College Publishers.

Gansneder, B. M., Caldwell, M. S., Morris, J., Napier, J. D., \& Bowen, L. S. (1977). An Analysis of the Association between Teachers' Classroom Objectives and Activities. [Article]. Journal of Educational Research, 70(4), 175-179.

Greeno, J. G. (1976). Cognitive objectives of instruction: Theory of knowledge for solving problems and answering questions. In D. Klahr (Ed.), Cognition and Instruction (pp. 123-159). Hillsdale, NJ: Lawrence Erlbaum Associates.

Gronlund, N. E. (1985). Stating behavioral objectives for classroom instruction. New York: Macmillan.

Gronlund, N. E. (2004). Writing instructional objectives for teaching and assessment. New York: Prentice Hall.

Gropper, G. L. (1983). A metatheory of instruction: A framework for analyzing and evaluating instructional theories and models. In C. M. Reigeluth (Ed.), Instructional design theories and models: An overview of their current status. Hillsdale, NJ: Lawrence Erlbaum Associates.

Hartley, J. \& Davies, I. K. (1976). Preinstructional strategies: The role of pretests, behavioral objectives, overviews, and advance organizers. Review of Educational Research, 46(2), 239265.

IMS Global Learning Consortium. (2002). IMS Reusable Definition of Competency or Educational Objective - Information Model Retrieved August 9, 2010, 2010, from http://www.imsglobal.org/competencies/rdceov1p0/imsrdceo_infov1p0.html\#1442598

Johnson, C. C. \& Sherman, J. E. (1975). Effects of behavioral objectives on student achievement in ISCS. [Article]. Science Education, 59(2), 177-180.

Leigh, H. N. \& Tracey, M. W. (2010). A review and new framework for instructional design practice variation research. Performance Improvement Quarterly, 23(2), 33-46.

Low, W. C. (1980). Changes in instructional development: The aftermath of an information processing takeover in psychology. Journal of Instructional Development, 4(2), 10-18.

MacDonald-Ross, M. (1973). Behavioral objectives: A critical review. Instructional Science, 2, 1 - 52.

Mager, R. (1962). Preparing instructional objectives. San Francisco: Fearon.

Martin, W. J. \& Bell, P. E. (1977). The use of behavioral objectives in instruction of basic vocational science students. [Article]. Journal of Research in Science Teaching, 14(1), 1-11.

Melton, R. F. (1978). Resolution of conflicting claims concerning the effect of behavioral objectives on student learning. Review of Educational Research, 48(2), 291-302.

Morrison, G. R., Ross, S. M., Kalman, H. K., \& Kemp, J. E. (2013). Designing effective instruction (7th ed.). Hoboken, NJ: John Wiley \& Sons, Inc.

Mulholland, P., Wolff, A., Zdrahal, Z., \& Collins, T. (2008). Blending Coherence and Control in the Construction of Interactive Educational Narratives from Digital Resources. Interactive Learning Environments, 16(3), 283-296. 
Novakowski, J. (2009). Classifying Classification. Science and Children, 46(7), 25-29.

Ormrod, J. (2011). Educational psychology: Developing learners. Boston: Pearson/Allyn \& Bacon.

Peček, M., Zuljan, M. V., Čuk, I., \& Lesar, I. (2008). Should assessment reflect only pupils' knowledge? [Article]. Educational Studies (03055698), 34(2), 73-82.

Posner, G. J. \& Strike, K. A. (1975). Ideology versus technology: The bias of behavioral objectives. Educational Technology, 15(5), 28-33.

Reti, P. G. (1975). Some guidelines on the classroom use of performance objectives. Programmed Learning and Educational Technology, 12(1), 29-33.

Saettler, P. (1990). The evolution of American educational technology. Englewood, CO: Libraries Unlimited.

Sandler, D. \& Kamins, M. A. (1987). Cognitive and affective dimensions of educational objectives: Scale development and measurement. Journal of Marketing Education, 9(3), 52-52.

Schamber, J. F. \& Mahoney, S. L. (2006). Assessing and Improving the Quality of Group Critical Thinking Exhibited in the Final Projects of Collaborative Learning Groups. Journal of General Education, 55(2), 103-137.

Snider, S. J. (1975). Cognitive and Affective Learning Outcomes Resulting from the Use of Behavioral Objectives in Teaching Poetry. Journal of Educational Research, 68(9), 333-338.

Teague, J. E. \& Michael, W. B. (1994). Preferences of science teachers for multiple-choice achievement test items at different levels. Educational \& Psychological Measurement, 54(4), 941-941.

Tessmer, M. \& Wedman, J. (1990). A layers-of-necessity instructional development model. Educational Technology Research \& Development, 38(2), 77-85.

Thiagarajan, S. (1973). Good objectives and bad: A checklist for behavioral objectives. Educational Technology, 8(8), 23-28.

Tumposky, N. R. (1984). Behavioral objectives, the cult of efficiency, and foreign language learning: Are they compatible? TESOL Quarterly, 18(2), 295-310.

Tyler, R. W. (1931). A generalized technique for conducting achievement tests. Educational Research Bulletin, 10(8), 199-208.

Tyler, R. W. (1971). Basic principles of curriculum and instruction. Chicago: University of Chicago Press.

Wedman, J. \& Tessmer, M. (1993). Instructional designers decisions and priorities: A survey of design practice. Performance Improvement Quarterly, 6(2), 43-57.

Wight, A. R. (1972). Beyond behavioral objectives. Educational Technology, 12(7), 9-14.

Winn, W. (1992). The assumptions of constructivism and instructional design. In T. M. Duffy \& D. $\mathrm{H}$. Jonassen (Eds.), Constructivism and the technology of instruction: A conversation. Hillsdale, NJ: Lawrence Erlbaum Associates. 
Woodruff, A. D. \& Kapfer, P. G. (1972). Behavioral objectives and humanism in education: A question of specificity. Educational Technology, 12(1), 51-55.

Correspondence: Gary R. Morrison, Professor of Instructional Design and Technology, Old

Dominion University, Education Building, Norfolk, Virginia, United States 